\title{
On the Coercive Force of Magnetic Iron Oxides*
}

\author{
Yasuo IMAOKA
}

\author{
TDK Electronics Co., Ltd., Central Research Lab., \\ 3800, Shimonuma, Hon-gyotoku, Ichikawa-shi, Chiba-prefecture
}

\section{Introduction}

As coercive force has a structure sensitive property, we consider several factors affecting the coercive force of magnetic iron oxide powders. In general these factors are classified as follows: magnetocrystalline anisotropy, (2) shape anisotropy, (3) magnetostriction anisotropy, (4) grain size dependence, (5) packing density, (6) directional relationship between two or more anisotropies, (7) coherent and incoherent rotation, (8) magnetic interaction between particles, (9) internal stress, etc... In addition it is desirable that as much information as possible on the change of internal structure of the particle during chemical reactions is available.

Many investigations dealt with the factors affecting on the coercive force of fine particles have been done. The writer has discussed the coercive force of $\mathrm{Fe}_{3} \mathrm{O}_{4}$ $-\gamma \mathrm{Fe}_{2} \mathrm{O}_{3}$ system fine powders and reported the abnormal increase and aging effect of coercive force in it. The writer has investigated the causes of these phenomena and effects and reached the undermentioned conclusion.

$\mathrm{A} \mathrm{Fe}_{3} \mathrm{O}_{4}$ fine powder consists of many small crystallines. This is due to the crystallization process of powder and chemical reaction such as dehydration, reduction and oxidation. We can follow these processes by electronicroscopy. The oxidation of the powder having these structures proceeds probably heterogeneously by means of a nucleation process. As the resultant small nuclei of $\gamma \mathrm{Fe}_{2} \mathrm{O}_{3}$ disperse in $\mathrm{Fe}_{3} \mathrm{O}_{4}$ matrix, they grow gradually and the number of them increases. According to these mechanism the abnormal increase of $\mathrm{Fe}_{3} \mathrm{O}_{4}-\gamma \mathrm{Fe}_{2} \mathrm{O}_{3}$ system powders is explained by the magnetic behavior of the thermally stable single domain nuclei of $\gamma \mathrm{Fe}_{2} \mathrm{O}_{3}$ or $\mathrm{Fe}_{3} \mathrm{O}_{4}$, or by the misfit of the lattice constant between matrix and nuclei.

Since the matrix and nuclei are also ferromagnetic in this system, the magnetic interactions between these two phases are not negligible. This makes to be difficult to explain the abnormality of coercive force, and this interaction is not yet theoretically explained clearly. To avoid this difficulty a chemical reaction which alters the magnetic properties of the product with respect to the starting material (i. e. ferromagnetic to nonmagnetic or vice versa) would be suitable for this purpose. The suitable reactions are as follows:

\footnotetext{
* Presented partly at 33rd Annual Meeting of Electrochemical Soc. Japan held on April 6, 1966 in Tokyo, and 34th Annual Meeting of Electrochemical Soc. Japan held on March 29, 1967 in Tokyo.
} 
(a) $\gamma \mathrm{Fe}_{2} \mathrm{O}_{3} \rightarrow a \mathrm{Fe}_{2} \mathrm{O}_{3}$ (epitaxial transformation with dislocations)

(b) $a \mathrm{Fe}_{2} \mathrm{O}_{3} \rightarrow \mathrm{Fe}_{3} \mathrm{O}_{4}$ (epitaxial reduction with dislocations)

(c) $\gamma \mathrm{Fe}_{2} \mathrm{O}_{3} \cdot \mathrm{H}_{2} \mathrm{O} \rightarrow \gamma \mathrm{Fe}_{2} \mathrm{O}_{3}$ (two-phase topotactic dehydration)

In this report about the above-mentioned reactions the change of the coercivity is measured and the mechanism of coercivity is discussed.

\section{Experimental}

In the reaction (a) and (b) acicular and granular type iron oxides are used. They are the same as used in the author's previous report. ${ }^{1}$,2) And in the reaction (c) $\gamma \mathrm{Fe}_{2} \mathrm{O}_{3} \cdot \mathrm{H}_{2} \mathrm{O}$ is made by the pyridine method $^{3)}$. That is, pure pyridine is added to the ferrous chloride aqueous solution and oxygen is bubbled into this solution. The color of the resultant solution changes from bluish green to yellowish brown. The ferrous hydroxide solution is oxidized at room temperature for 30 minutes $\sim 1$ hour. After washing $\gamma \mathrm{Fe}_{2} \mathrm{O}_{3} \cdot \mathrm{H}_{2} \mathrm{O}$ powder is dryed at room temperature. $\mathrm{X}$-ray diffraction pattern showed to be $\gamma \mathrm{Fe}_{2} \mathrm{O}_{3} \cdot \mathrm{H}_{2} \mathrm{O}$ and the acicular axis of the powder is about $0.4 \mu$ long. In the reaction (a) the sample is analysed by the DTA method and then the reaction temperature of $\gamma \rightarrow a$ transition is decided. Fig. 1 shows the DTA diagram of acicular

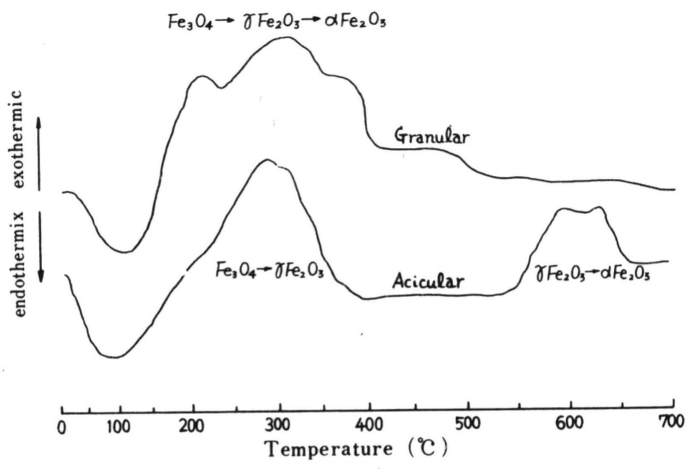

Fig. 1 DTA analysis and granular $\mathrm{Fe}_{3} \mathrm{O}_{4}$. As for acicular type $\gamma \mathrm{Fe}_{2} \mathrm{O}_{3}$ transforms to $a \mathrm{Fe}_{2} \mathrm{O}_{3}$ in the range of $560 \sim 650^{\circ} \mathrm{C}$, the reaction is done at $600^{\circ} \mathrm{C}$. The transformation perfectly finishes at $600^{\circ} \mathrm{C}$ for 3 hours in acicular type. Granular type $\gamma \mathrm{Fe}_{2} \mathrm{O}_{3}$ begins to transform to $a \mathrm{Fe}_{2} \mathrm{O}_{3}$ at the same time when $\mathrm{Fe}_{3} \mathrm{O}_{4}$ finishes to oxidize to $\gamma \mathrm{Fe}_{2} \mathrm{O}_{3}$ at $250^{\circ} \mathrm{C}$. So the experiment is done at $300^{\circ} \mathrm{C}$ in air. The transformation finishes at $300^{\circ} \mathrm{C}$ for 3 hours in granular type.

In the reaction (b) the sample used is the $\gamma \mathrm{Fe}_{2} \mathrm{O}_{3}$ powder which is confirmed to be transformed perfectly by the X-ray diffraction. The sample is put into the silica tube and is reduced by hydrogen at $350 \sim 500^{\circ} \mathrm{C}$ under several hydrogen partial pressures. The samples having several reduction state are obtained.

In the reaction (c) the dehydration begins at about $50^{\circ} \mathrm{C}$ and finishes at about $300^{\circ} \mathrm{C}$. As shown in Fig. 2, the experiment is proceeded at $200 \sim 400^{\circ} \mathrm{C}$.

Resultant products are analysed quantitatively by X-ray diffraction (diffract-

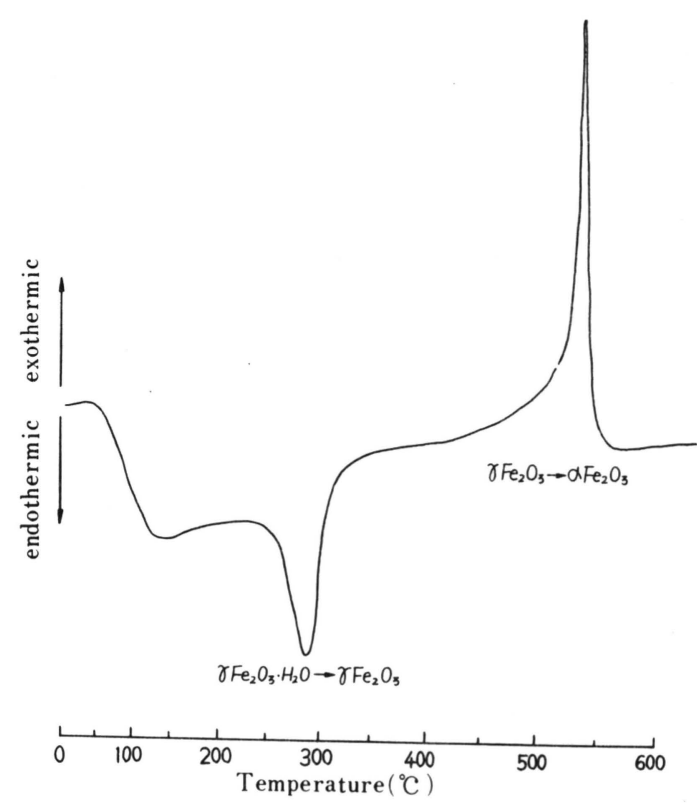

Fig. 2 DTA analysis 
meter method). For example in the reaction (a) the diffraction angle of (311) of $\gamma \mathrm{Fe}_{2} \mathrm{O}_{3}$ almost coincides with the one of (110) of $a \mathrm{Fe}_{2} \mathrm{O}_{3}$. So these diffraction lines are not suitable for quantitative analysis, the intensity of (220) diffraction of $\gamma \mathrm{Fe}_{2} \mathrm{O}_{3}$ and (104) of $a \mathrm{Fe}_{2} \mathrm{O}_{3}$ are used.

The gauging curve of mixture of $\gamma \mathrm{Fe}_{2} \mathrm{O}_{3}$ and $a \mathrm{Fe}_{2} \mathrm{O}_{3}$ is prepared. The samples were measured by the same condition which is prepared the gauging curve and by means of referring the intensities of sample and reference the $\gamma \mathrm{Fe}_{2} \mathrm{O}_{3} /$ $a \mathrm{Fe}_{2} \mathrm{O}_{3}$ ratio is determined. In the reaction (b), as the diffraction pattern of $\mathrm{Fe}_{3} \mathrm{O}_{4}$ is almost the same the one of $\gamma \mathrm{Fe}_{2} \mathrm{O}_{3}$, the same diffraction lines in the reaction (a) are used. In the experiment (c) mixture of two phases is not got. It is found from the experiments that after either the breakdown of the $\gamma \mathrm{Fe}_{2} \mathrm{O}_{3} \cdot \mathrm{H}_{2} \mathrm{O}$ lattice or the division of the lattice into small $\gamma \mathrm{Fe}_{2} \mathrm{O}_{3}$ units, rearrangement of the $\gamma \mathrm{Fe}_{2} \mathrm{O}_{3}$ lattice takes place.

\section{Results}

\subsection{Reaction (a): $\gamma \mathrm{Fe}_{2} \mathrm{O}_{3} \rightarrow a \mathrm{Fe}_{2} \mathrm{O}_{3}$}

According to the transformation the saturation magnetization $\mathrm{Im}$, coercive force $\mathrm{Hc}$ and rectangular ratio $\mathrm{Ir} / \mathrm{Im}$ changes as shown Fig. 3 (acicular) and Fig. 4(granular). Im increases according to the proceeding of transformation and

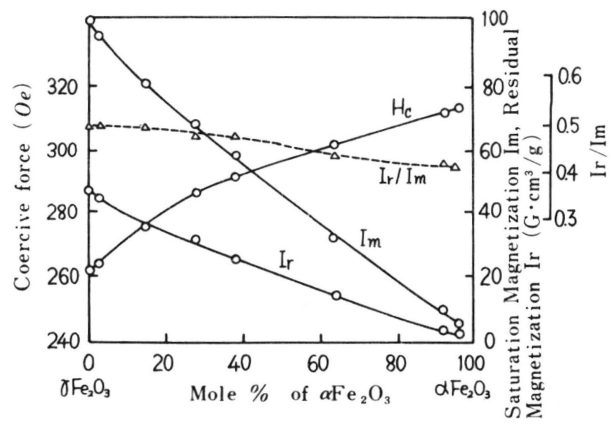

Fig. 3 Magnetic properties of $\gamma \mathrm{Fe}_{2} \mathrm{O}_{3}-a \mathrm{Fe}_{2} \mathrm{O}_{3}$ system (Acicular)

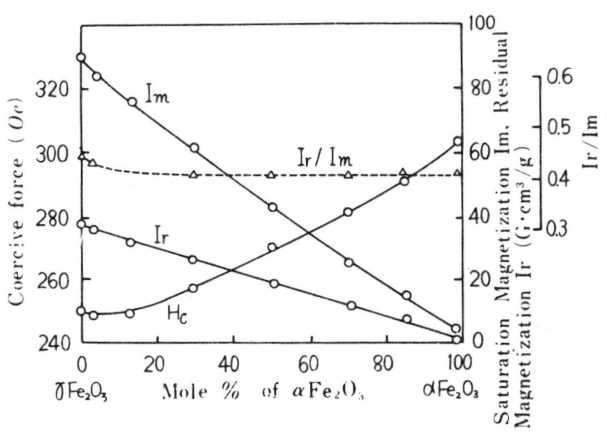

Fig. 4 Magnetic properties of $\gamma \mathrm{Fe}_{2} \mathrm{O}_{3}-a \mathrm{Fe}_{2} \mathrm{O}_{3}$ system (Granular)

Im becomes to zero at the end of the reaction. The rectangular ratio is in the range of $0.45 \sim 0.5$ from the begining to the end of the transformation. The coercivity of $\gamma \mathrm{Fe}_{2} \mathrm{O}_{3}$ is about $250 \mathrm{Oe}$, and according to the proceeding of the transformation it gradually increases. At almost the end point of the reaction it be-

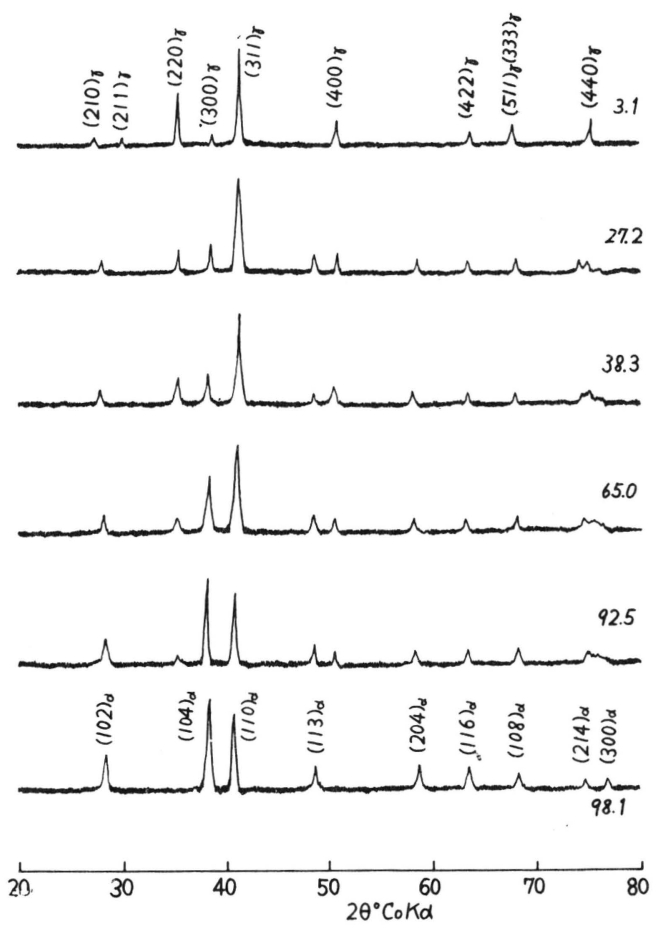

Fig. 5 X-ray diffraction patterns of $-a \mathrm{Fe}_{2} \mathrm{O}_{3}$ system system (Acicular)(numbers indicate mole $\%$ of $\left.a \mathrm{Fe}_{2} \mathrm{O}_{3}\right)$ 
comes about 300 Oe both in acicular and granular type powders, By the X-ray diffraction the sample is mixture of two phases $\left(\gamma \mathrm{Fe}_{2} \mathrm{O}_{3}\right.$ and $\left.a \mathrm{Fe}_{2} \mathrm{O}_{3}\right)$ (see Fig. 5). The lattice constant of $\gamma \mathrm{Fe}_{2} \mathrm{O}_{3}$ and $a \mathrm{Fe}_{2} \mathrm{O}_{3}$ is determined independently at room temperature; for $\gamma \mathrm{Fe}_{2} \mathrm{O}_{3}, \mathrm{a}_{0}=8.34 \mathrm{~A}^{\circ}$ for $a \mathrm{Fe}_{2} \mathrm{O}_{3} \mathrm{a}=5.03 \mathrm{~A}^{\circ} \quad \mathrm{c}=13.67 \mathrm{~A}^{\circ}$ These show good agreement to the data on ASTM cards.

\subsection{Reaction (b); $a \mathrm{Fe}_{2} \mathrm{O}_{3} \rightarrow \mathrm{Fe}_{3} \mathrm{O}_{4}$}

According to the reduction the changes of magnetic properties are shown in Fig. 6 (acicular) and Fig. 7 (granular). Satura-

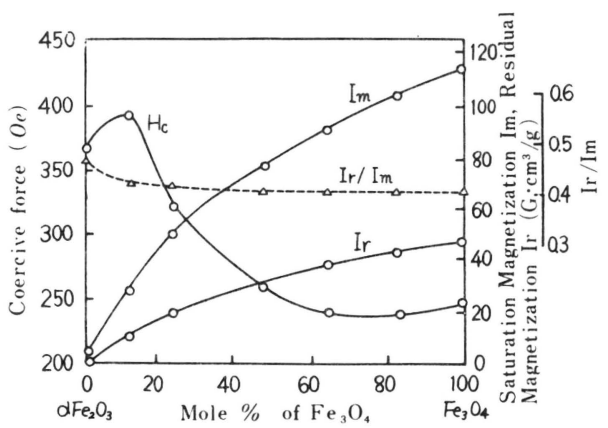

Fig. 6 Magnetic properties of $a \mathrm{Fe}_{2} \mathrm{O}_{3}-\mathrm{Fe}_{3} \mathrm{O}_{4}$ system (Acicular)

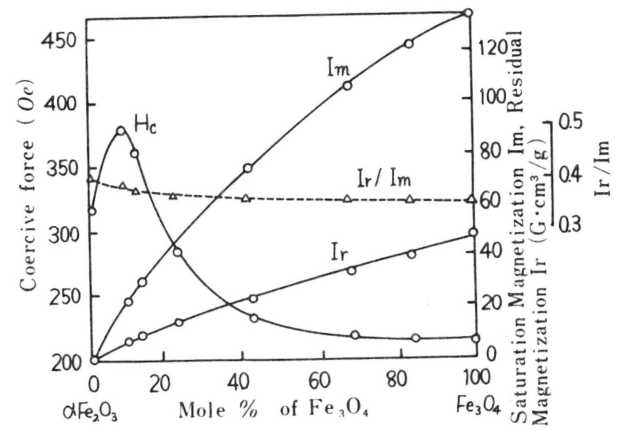

Fig. 7 Magnetic properties of $a \mathrm{Fe}_{2} \mathrm{O}_{3}-\mathrm{Fe}_{3} \mathrm{O}_{4}$ system (Granular)

tion magnetization Im and residual magnetization Ir increase according to the proceeding reduction, but the rectangular ratio $\mathrm{Ir} / \mathrm{Im}$ is almost constant through the reaction. The change of coercive force is characteristic. In acicular powders the coercive force becomes nearly 400 Oe just after the beginning the reduction. The corresponding composition of this maximum coercivity is $a \mathrm{Fe}_{2} \mathrm{O}_{3} / \mathrm{Fe}_{3} \mathrm{O}_{4}$ $=15 / 85$ in mole ratio. The coercive force rapidly decreases according to the reaction, at the composition $a \mathrm{Fe}_{2} \mathrm{O}_{3} / \mathrm{Fe}_{3} \mathrm{O}_{4}$ $=60 / 40$ the coercivity reaches almost the same value which is the one of $\mathrm{Fe}_{3} \mathrm{O}_{4}$. These magnetic phenomena are similar to the one in the granular type powder. In granular type powder the maximum coercivity seen in the beginning of the reduction is about $370 \mathrm{Oe}$, and the composition $a \mathrm{Fe}_{2} \mathrm{O}_{3} / \mathrm{Fe}_{3} \mathrm{O}_{4}$ corresponding to the maximum coercive force is nearly $12 / 88$ in mole ratio.

The sample composition is two-phase mixture of $a \mathrm{Fe}_{2} \mathrm{O}_{3}$ and $\mathrm{Fe}_{3} \mathrm{O}_{4}$. Small amount of $\gamma \mathrm{Fe}_{2} \mathrm{O}_{3}$ seems to form in $\mathrm{Fe}_{3} \mathrm{O}_{4}$ but it is not confirmed by the $\mathrm{X}$ ray diffraction. The lattice constant of each phases is as follows: $\mathrm{a}=5.03 \sim 5.04 \AA$, $\mathrm{c}=13.7 \sim 13.8 \AA$ for $a \mathrm{Fe}_{2} \mathrm{O}_{3}$, and $\mathrm{a}_{\mathrm{o}}=8.39$ $\sim 8.04 \AA$ for $\mathrm{Fe}_{3} \mathrm{O}_{4}$. The difference in the lattice constant with the degree of reduction is not found.

\subsection{Reaction (c); $\gamma \mathrm{Fe}_{2} \mathrm{O}_{3} \cdot \mathrm{H}_{2} \mathrm{O} \rightarrow \gamma \mathrm{Fe}_{2} \mathrm{O}_{3}$}

The X-ray diffraction pattern of this reaction is shown in Fig. 8 and the magnetic properties are shown in Table 1. From X-ray diffraction and other measurements the reaction is different from both the reaction (a) and (b) and two phase mixture is not found. When the dehydration temperature is raised and the dehydration time is prolonged, the halfwidth value of diffraction line of $\gamma \mathrm{Fe}_{2} \mathrm{O}_{3}$ $\cdot \mathrm{H}_{2} \mathrm{O}$ increases gradually. When the dehydration is carried out at $250^{\circ} \mathrm{C}, 0.5 \mathrm{hr}$, the diffraction pattern of $\gamma \mathrm{Fe}_{2} \mathrm{O}_{3} \cdot \mathrm{H}_{2} \mathrm{O}$ clearly disappeare and the pattern of 

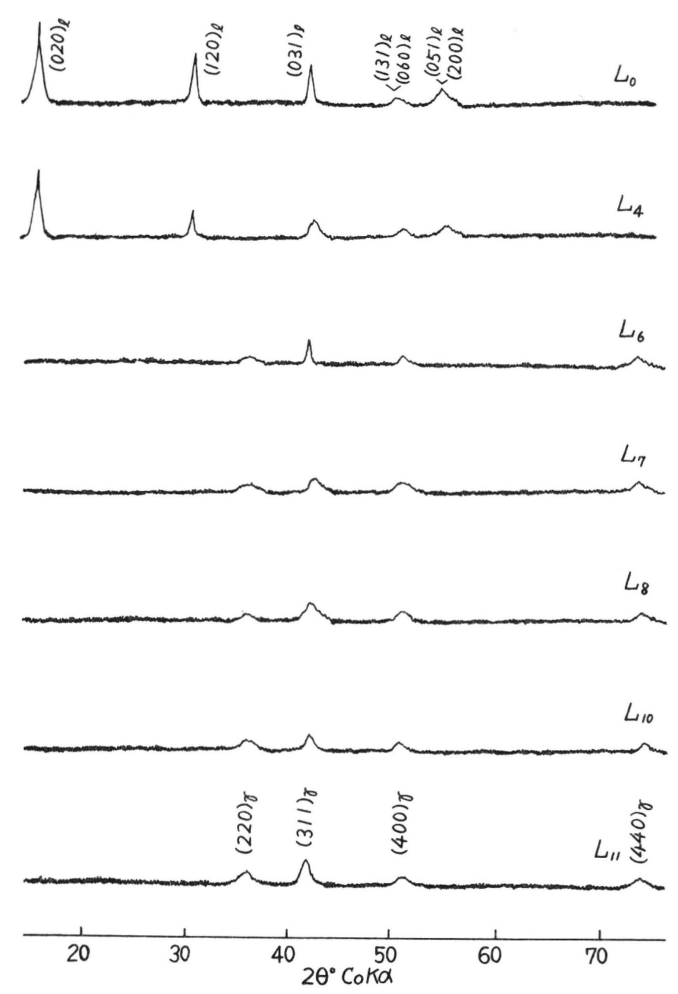

Fig. 8 X-ray diffraction patterns of $\gamma \mathrm{Fe}_{2} \mathrm{O}_{3}-\mathrm{H}_{2} \mathrm{O}$ $\gamma \mathrm{Fe}_{2} \mathrm{O}_{3}$ $\gamma \mathrm{Fe}_{2} \mathrm{O}_{3}$ comes to be clear for the dehydration of $300^{\circ} \mathrm{C}, 0.5 \mathrm{hr}$. In the Table 1 the crystalline size calculated by the Scherrer's equation is shown. In this calculation diffractions from (031) of $\gamma \mathrm{Fe}_{2} \mathrm{O}_{3} \cdot \mathrm{H}_{2} \mathrm{O}$ and (311) of $\gamma \mathrm{Fe}_{2} \mathrm{O}_{3}$ are used. By the breaking down of $\gamma \mathrm{Fe}_{2} \mathrm{O}_{3}$ $\cdot \mathrm{H}_{2} \mathrm{O}$ lattice the crystalline size decreases from $180 \AA$ to $40 \AA$ and according to the proceeding of dehydration the size recovers slowly and it becomes about $100 \AA$ of $\gamma \mathrm{Fe}_{2} \mathrm{O}_{3}$.

The saturation magnetization of samples is able to measured about the sample $L_{1}$ and $L_{2}$ which is slightly dehydrated and its value increase with the proceeding of dehydration. The time when the residual magnetization becomes to be measurable is almost the same when the coercive force also becomes to be measurable and the lattice of $\gamma \mathrm{Fe}_{2} \mathrm{O}_{3} \cdot \mathrm{H}_{2} \mathrm{O}$ is broken down.

According to the proceeding of dehydration the coercive force, residual magnetization and $\mathrm{Ir} / \mathrm{Im}$ also increases.

Table 1 Dehydration of $\gamma \mathrm{Fe}_{2} \mathrm{O}_{3} \cdot \mathrm{H}_{2} \mathrm{O}$ and Its Magnetic Properties

\begin{tabular}{l|c|c|c|c|c|c|c|c}
\hline \multirow{2}{*}{ Sample } & \multicolumn{2}{|l|}{ Dehydration } & Coercivity & $\begin{array}{c}\text { Residual } \\
\text { magneti- } \\
\text { zation } \\
I_{r}\left(\mathrm{G} \cdot \mathrm{cm}^{3} / \mathrm{g}\right)\end{array}$ & $\begin{array}{c}\text { Saturation } \\
\text { magneti- } \\
\text { zation } \\
I_{m}\left(\mathrm{G} \cdot \mathrm{cm}^{3} / \mathrm{g}\right)\end{array}$ & $\begin{array}{c}\text { Rectangular } \\
\text { ratio }\end{array}$ & $\begin{array}{c}I_{r} / I_{m} \\
\text { Crystalline } \\
\text { size }\end{array}$ & $\begin{array}{c}\text { X-ray* } \\
\text { diffraction }\end{array}$ \\
\hline$\left.L_{0}{ }^{\circ} \mathrm{C}\right)$ & $(\mathrm{hr})$ & $\left(O_{e}\right)$ & 0 & 180 & $L$ \\
$L_{1}$ & 200 & 0.5 & 0 & 0 & 0 & 0 & 180 & $L$ \\
$L_{2}$ & 200 & 1.0 & 0 & 0 & 3.9 & 0 & 180 & $L$ \\
$L_{3}$ & 200 & 2.0 & 0 & 0 & 13.0 & 0 & 180 & $L$ \\
$L_{4}$ & 250 & 0.5 & 10 & 1.9 & 34.0 & 0.056 & 170 & $L$ \\
$L_{5}$ & 300 & 0.5 & 51 & 12.2 & 44.8 & 0.272 & 40 & $C$ \\
$L_{6}$ & 300 & 1.0 & 61 & 15.6 & 63.5 & 0.245 & 50 & $C$ \\
$L_{7}$ & 300 & 2.0 & 75 & 22.8 & 75.5 & 0.302 & 70 & $C$ \\
$L_{8}$ & 300 & 3.0 & 94 & 25.8 & 79.4 & 0.323 & 70 & $C$ \\
$L_{9}$ & 350 & 2.0 & 100 & 25.9 & 77.0 & 0.335 & 80 & $C$ \\
$L_{10}$ & 350 & 4.0 & 118 & 27.9 & 80.6 & 0.347 & 90 & $C$ \\
$L_{11}$ & 400 & 1.0 & 134 & 26.4 & 81.6 & 0.324 & 95 & $C$ \\
\hline
\end{tabular}

${ }^{*} \mathrm{~L}: \gamma \mathrm{Fe}_{2} \mathrm{O}_{3} \cdot \mathrm{H}_{2} \mathrm{O}, \mathrm{C}:{ }_{\gamma} \mathrm{Fe}_{2} \mathrm{O}_{3}$ 
In the reaction (c) the quantitative analysis of two plases components by the $\mathrm{X}$-ray diffraction is difficult.

\section{Discussion}

It is clear from the results that in the reaction (a) the saturation magnetization decreased according to the proceedings of dehydration, and the coercive force showed the maximum value at near the end point of the reaction. In the reaction (b) and (c) the saturation magnetization gradually increases according to the reaction. In the reaction (a), (b), and (c) the increases and decrease of magnetization is explained by the growth or diminution of ferromagnetic phase.

What is the cause of the maximum coercivity occured in the process of reaction (a) and (b)? As already mentioned, the reactions such as the dehydration, reduction and oxidation etc. of iron oxide powders was considered to proceed heterogeneously. The high magnitude electron microscopy explains that the iron oxide powder is composed of many crystallines, and some times it has tactiod structure. These structures is favorable to occur heterogenous chemical reactions. Many factors effecting on the coercivity are above-mentioned in the introduction of this paper. But in the reaction (a), (b) and (c) the preferable factors are (1) the single domain behavior of the nuclei and (2) internal striction caused by lattice misfit.

First the writer considers the factor (1). As the nuclei is ferromagnetic substance the size dependence of coercive force is very characteristic. According to the growth of nuclei, the magnetic behavior of the nuclei changes as follows; superparamagnetism $\rightarrow$ thermally stable single domain $\rightarrow$ multi-domain. The coercive force becomes the maximum value at single domain range. Takata showed the relationship between the grain size of single crystal iron oxide and coercivity, and the powder come to be superparamagnetic below $100 \AA$ in diameter ${ }^{4}$. In the reaction (a) the coercive force increases towards the decrease of ferromagnetic phase, so the maximum coercivity correspons to the grain size change from multi-domain to single domain. In the reaction (b) just after the starting of reaction the coercivity become the maximum and there-after decreases slowly according to the reaction. The former part of the coercive force change is correspondent to the state which is form superparamagnetism to single domain, the latter part is from single domain to multidomain. These changes of coercive force are seen in the aging of $2 \% \mathrm{Co}-\mathrm{Cu}$ alloy $\mathrm{s}^{5}$ ). In this case the change of coercive force is also explained by the magnetic behavior of single domain.

Second the factor (2) is considered the cause of the striction is the misfit of lattice constant between unclei and matrix. As in $\mathrm{Fe}_{3} \mathrm{O}_{4} \underset{\leftarrow}{\vec{*}} \gamma \mathrm{Fe}_{2} \mathrm{O}_{3}$ transformation which is between cubic lattice and in which the spinel-like lattice is inherited, the maximum misfit between these lattices is calculated to be $6 \times 10^{-3}$. On the contrary to the reaction (a) and (b) the lattice transformes between cubic and hexagonal symmetry and the misfit of which vertical directions to $0^{2-}$ closest packing comes to about $\mathbf{1 0}^{-1}$. But in practical by Heidenreich-Shockley type dislocation the lattice energy is decreased.

The transformation (a), disscussed by Kachi6) et al., proceeds by the formation of dislocations and diffusion of ions. The formation of dislocation breaks into small island of $\gamma \mathrm{Fe}_{2} \mathrm{O}_{3}$ dispersed in $a$ $\mathrm{Fe}_{2} \mathrm{O}_{3}$. The rectangular ratio is almost between $0.4 \sim 0.5$.

The magnetic nuclei are thought to be uniaxial particles caused the internal stress 
or having the shape anisotropy. If the particle is spherical and the origin of the magnetic anisotropy is magneto-crystalline anisotropy, the coercivity is expected to be about 200 Oe and the $\mathrm{Ir} / \mathrm{Im}$ value to be about 0.83 .

In the reaction (b) the same situation which is above-mentioned is expected. It is found in this experiment that in the reaction (a) and (b) the expected coercive force is maximum 300 Oe for the dispersed ferromagnetic nuclei.

In the reaction (c) when the $\gamma \mathrm{Fe}_{2} \mathrm{O}_{3}$ $\cdot \mathrm{H}_{2} \mathrm{O}$ lattice begins to break into small units, $\gamma \mathrm{Fe}_{2} \mathrm{O}_{3}$ lattice begins to form. By the $\mathrm{X}$-ray diffraction the crystalline size is about $40 \AA$. This size is magnetically superparamagnetic and so it is natural that the coercive force and remanence is not measured at room temperature. Proceeding the reaction the $\gamma \mathrm{Fe}_{2} \mathrm{O}_{3}$ crystal gradually grow and according to this $\mathrm{Hc}$, Ir and Im increase. The crystalline size of perfectly dehydrated $\gamma \mathrm{Fe}_{2} \mathrm{O}_{3}$ is about $110 \AA$. This size is critical size to be single domain at room temperature.

Wiliams ${ }^{7}$ and Welo $^{3)}$ investigated the reaction (c) by the $\mathrm{X}$-ray diffraction and magnetically, and its results consists of the writers results. The reason why the maximum of coercive force was not seen is that the crystalline of $\gamma \mathrm{Fe}_{2} \mathrm{O}_{3}$ is not sufficiently large for the single domain. If the crystalline size of $\gamma \mathrm{Fe}_{2} \mathrm{O}_{3}$ is grown larger and so it becomes to be more stable magnetically, the maximum peak of coercivity would be seen.

\section{Summary}

The coercive force of iron oxide powders are measured in the reaction of which starting material or resultant material is ferromagnetic and the other is non-magnetic. In reaction (a), $\gamma \mathrm{Fe}_{2} \mathrm{O}_{3}$ transforms to $a \mathrm{Fe}_{2} \mathrm{O}_{3}$, the coercive force of fine powders shows maximum value at the end point of the transformation. In reaction (b), reduction of $a \mathrm{Fe}_{2} \mathrm{O}_{3}$ to $\mathrm{Fe}_{3} \mathrm{O}_{4}$, at the beginning of the reaction the coercivity shows the maximum.

If these reactions proceed by the nucleation process accompanying with the formation of dislocation and ion diffusion, the behavior of coercivity through these reaction can be explained by the size dependency of ferromagnetic nuclei distributed in non magnetic matrix and the crystallographic misfit between nuclei and matrix. In these situation the ferromagnetic interaction between the ferromagnetic nuclei themselves can be neglected, then we consider that the measured maximum coercive force does not contain the interaction part. The maximum coercive force is about 300 Oe in the reaction (a) and (b). As squareness ratio of the hysteresis loop is $0.4 \sim 0.5$, the writer considers that the origin of these coercive force is probably due to ferromagnetic nuclei with shape anisotropy or magnetostrained nuclei. The origin of abnormal increase of coercive force in $\mathrm{Fe}_{3} \mathrm{O}_{4}-\gamma \mathrm{Fe}_{2} \mathrm{O}_{3}$ system powders which is previously reported by the writer may be explained by the abovementioned stress effect according to heterogeneous oxidation.

In the reaction (c), $\gamma \mathrm{Fe}_{2} \mathrm{O}_{3} \cdot \mathrm{H}_{2} \mathrm{O} \cdot \mathrm{de}$ hydration to $\gamma \mathrm{Fe}_{2} \mathrm{O}_{3}$, the two-phase mixture is not got, and the maximum peak of coercive force is not shown. The cause of these results are due to that the crystalline of $\gamma \mathrm{Fe}_{2} \mathrm{O}_{3}$ particle is too small and therefore the particle can not behave as thermally stable single domain. For the procedure of this experiment the writer is grateful to Professor Yasushi Hoshino and Associated Professor Minoru Sato of Tokyo Institute of Technology and thanks Dr. Masanori Kato of Tokyo Institute of Technology for the X-ray diffraction. The writer also thanks Dr. 
Teitaro Hiraga, Dr. Makoto Inagaki and Dr. Mamoru Namikawa of TDK Electronics.

\section{Literature:}

1) Y. Imaoka, M. Sato, Y. Hoshino, J. Electrochem, Soc. Japan33, 19 (1965).

2) Y. Imaoka, ibid. 33, 1 (1965).

3) L. A. Welo, O. Baudish, Phil. Mag. 17, 753
(1934).

4) T. Takada, M. Kiyama, Y. Yamaguchi, Annual Meeting of Phys. Soc. Japan, April, (1961).

5) T.Mitui, J. Phys. Soc. Japan, 13, 549(1958) (1958).

6) B. Kachi, K. Momiyama, S. Shimizu, ibid. 18, 106 (1963).

7) R. D. Williams, J. Thewlis, Trans. Faraday Soc. 27, 767 (1931).

\title{
One Approach to the Fabrication of Hyper Abrupt Junction Diode
}

\author{
Yoshio NisHI \\ Semiconductor Engineering Department, \\ Tokyo Shibaura Electric Co., Ltd., Kawasaki, Japan
}

Received Noy. 20, 1967

\begin{abstract}
Planar hyper abrupt junction diode is fabricated by means of epitaxy and diffusion. Doped impurity in an epitaxial layer which governs the capacitance-voltage characteristics is antimony, and boron is applied to form a $p$-n junction in the epitaxial layer. The antimony concentration profiles are theoretically designed to yield the desired diode characteristics. The deformation of the antimony profile during the diffusion of boron is too small to seriously affect the capacitance-voltage characteristics. There exists, hence, fairly good coincidence between the theoretical prediction and the experimental result.

The merits and the demerits are also discussed qualitatively from the view points of both designing and fabrication of hyper abrupt junction.
\end{abstract}

\section{Introduction}

The hyper abrupt junction devices ${ }^{1 \sim 3}$ ) have been extensively utilized for frequency modulation, phase modulation, tuning etc. in the range of wide-spread operating frequency. Recently the in- creasing demands to the hyper abrupt junction diode have forced the development in manufacturing technology such as double diffusion method ${ }^{3)}$ and epitaxial growth method 4$), 5$ ) in addition to alloydiffusion method ${ }^{2}$. 